\title{
Human embryonic stem cell lines with CCR5-del32 allele conferring resistance to HIV
}

\author{
Ekaterina Pomerantseva, Valeri Kukharenko, Adam Goodman, Oleg Verlinsky, \\ Svetlana Rechitsky, Anver Kuliev*
}

Reproductive Genetics Institute, Chicago, USA.

*Corresponding Author: anverkuliev@hotmail.com

Received 24 June 2011; revised 29 July 2011; accepted 12 August 2011.

\begin{abstract}
A 32bp deletion in the chemokine receptor 5 (CCR5) gene (CMKBR5) was shown to be linked to HIV resistance. Bone marrow transplantation from the homozygous CCR5-del32 donor to a CDC Stage 2 HIV-positive recipient was demonstrated to confer a HIV resistance, resulting in discontinuation of antiretroviral therapy. In search for an unlimited source of CCR5-del32 cells for transplantation purposes, we tested $137 \mathrm{hu}$ man embryonic stem cell (hESC) lines from the Reproductive Genetics Institute's hESC lines collection, and report here the finding of $12 \mathrm{hESC}$ lines with the CCR5-del32 allele, one of which represents a unique partenogenetic ESC line containing two copies of this deletion and may be studied for utility in stem cell transplantation treatment of HIV.
\end{abstract}

Keywords: Human Embryonic Stem Cell Lines; Resistance to HIV; CCR5-del32 Allele; Parthenogenetic Stem Cell Line with Two Copies of CCR5-del32 Allele; Stem Cells Transplantation

\section{INTRODUCTION}

The first HIV-positive individual has recently been successfully cured via bone marrow transplantation from the unrelated donor, who was chosen not only by human leukocyte antigen (HLA) matching, but also for having a homozygous polymorphism in the chemokine receptor 5 (CCR5) gene CMKBR5 [1]. Although CCR5del32 allele was linked to HIV resistance long time ago, providing an immense promise of being able to treat HIV positive patients [2], finding acceptable donor matches homozygous for the CCR5del32 presented a real challenge. Of course, as in other conditions treatable by allogeneic bone marrow transplantation, finding an HLA match related donor is ideal, but probability of finding such a match is extremely low [3]. Further, this is almost unrealistic if there is a need for a related or even unrelated donor with a specific allele, like CCR5-del32. Clearly, transplantation from an adult unrelated donor is limited by the availability of fully HLA matched donors, while an increased HLA disparity provides for lower survival rates and a higher chance of graft-versus-host disease (GVHD).

The use of unrelated umbilical cord blood (UCB), which is a valuable source of hematopoietic stem cells, is presently an established alternative to bone marrow transplantation. Its potential advantages was expected to be the possibility of using UCB with one or two HLA mismatches, reducing conditioning intensity and avoiding the risk of severe GVHD [4]. These effects seemed to be due to the "naïve" nature of umbilical cord lymphocytes [5]. However, the major disadvantage of UCB is a reduced engraftment, which is due to the limited number of CD34 stem cells obtainable from a UCB sample, limiting the application of UCB transplantation to alder children.

On the other hand, with the current progress in stem cell research, there is presently an important potential alternative source of stem cell for transplantation, residing in human embryonic stem cell (hESC) lines, which are readily available in a few centers around the world [6,7]. Since embryonic stem cells may be expected to have even more "naïve" immunological features compared to UCB stem cells, they should allow for similarly high acceptable HLA disparities, thereby making patient-donor matching much more permissible, to avoid aggressive conditioning before and after transplantation, a critical advantage for patients with serious health conditions [8,9]. Also, one of important advantages of this option is that hESC collections provide an unlimited source, as they may be expanded virtually without limit, so a single hESC line can potentially be used for the transplantation treatment of any number of recipients.

The Reproductive Genetics Institute has currently developed the world's largest collection of hESC lines, $[6,7]$ which has been screened for the presence of the CCR5- 
del32 allele. This paper presents the first results of the study, which revealed $12 \mathrm{hESC}$ lines containing this gene, of which one is unique parthenogenetic line with two copies of CCR5-del32.

\section{MATERIAL AND METHODS}

Using our ongoing practice of preimplantation genetic diagnosis (PGD), we initiated the development of the hESC lines with normal and abnormal genotypes [6-7], which were characterized by cytogenetic analysis, and a set of ESC criteria, including the presence of octamerbinding transcription factor-4 (Oct-4), tumor rejection antigen-2-39 (TRA-2-39), high molecular weight glycoproteins (antibodies TRA-1-60, TRA-1-81), and stage specific embryonic antigens (SSEA-3, SSEA-4). Overall, this collection is presently contains a total of $327 \mathrm{hESC}$ lines, including 240 normal and 87 with genetic and chromosomal disorders (www.stemride.com) [6-7]. The lines were maintained in vitro for up to over a dozen passages before freezing in sufficient amounts.

To screen these hESC lines for the CCR5del32 deletion, the cells were removed from cryogenic storage, washed in PBS, and were placed directly into a lysis solution, consisting of $0.5 \mu \mathrm{L}$ of $10 \mathrm{x}$ PCR buffer, $0.5 \mu \mathrm{L}$ of $1 \%$ Tween $20,0.5 \mu \mathrm{L}$ of $1 \%$ Triton $\mathrm{X}-100,3.5 \mu \mathrm{L}$ of water, and $0.05 \mu \mathrm{L}$ of Proteinase $\mathrm{K}(20 \mathrm{mg} / \mathrm{mL}$ in $0.5 \mathrm{~mL}$ PCR tube). After spinning down, the samples were covered with 1 drop of mineral oil and incubated at $45^{\circ} \mathrm{C}$ for 15 minutes in a thermal cycler. Proteinase $\mathrm{K}$ was then inactivated at $96^{\circ} \mathrm{C}$ for 20 minutes. Hot start PCR was performed at $72^{\circ} \mathrm{C}$ for 10 minutes, followed by denaturation at $95^{\circ} \mathrm{C}$ for 3 minutes. Round 1 PCR master mix consisted of dNTP $400 \mu \mathrm{M}, 1 \times$ PCR buffer, Taq polymerase $(2 \mathrm{U}), 1.5 \mathrm{mM}$ magnesium dichloride, $6 \%$ dimethylsulfoxide, and $0.5 \mu \mathrm{M}$ of outside upstream and downstream primers for the mutation in a final volume of $50 \mu \mathrm{L}$. The cycling conditions for the first round of PCR were as follows: $95^{\circ} \mathrm{C}$ for 30 seconds, $55^{\circ} \mathrm{C}$ for 1 minute 30 seconds, $72^{\circ} \mathrm{C}$ for 45 seconds, for 5 cycles; during the following 23 cycles, the annealing temperature was gradually decreased from 55 to 45 degrees; with a final incubation at $72^{\circ} \mathrm{C}$ for 10 minutes.

We designed the outer primers CCR5-1 GCGTCTCTCCCAGGAATCATC and CCR5-2 GATTCCCGAGTAGCAGATGACC for performing the first round of amplification, and inner primer CCR5-3 GCGTCTCTCCCAGGAATCATC for second round of hemi-nested (CCR5-1 and CCR5-3) PCR. The cycling conditions for the second round of PCR were as follows: $92^{\circ} \mathrm{C}$ for 30 seconds, $55^{\circ} \mathrm{C}$ for 30 seconds, $72^{\circ} \mathrm{C}$ for 30 seconds, for a total of 30 cycles; and followed by a final 10 -minute incubation at $72^{\circ} \mathrm{C}$.

Primers for chromosome specific microsatellite mark- ers were added to identify the copy number and parental origin of the polymorphic markers, used for aneuploidy testing of chromosomes 13, 16, 18, 21, 22 and X [10].

The PCR product was assessed by gel electrophoresis and Ethidium Bromide staining. As shown in the Figure 1, the normal allele corresponds to the $141 \mathrm{bp}$ band while the CCR5-del32 allele corresponds to 109 bp band.

Stem cell samples from the lines containing the mutant gene were then expanded. Frozen samples were briefly thawed and then delicately spun down at 500 Gs for 10 minutes. After removing the cryo-preservation media, the cells were resuspended in a pre-warmed serum free culture media. The cells were then plated onto mitotically blocked human derived feeder layers set in a gelatin coating. Typically the culture medium was changed every other day, carefully evaluating changes in the growth rate and level of differentiation in the stem cell colonies. The passage intervals were based on the expert observation and varied from 4 - 15 days between passages. Passages where conducted with the use of $1 \mathrm{mM}$ EDTA with the incubation times adjusted to increase the proportion of healthy undifferentiated colonies passed on to new cultures. During passages the cultures were also split to maintain an appropriate colony density based on the growth rate of the individual cell line. The stem cell lines were expanded until well established and cryopreserved. The genetic test of the cells from the expanded lines was then repeated to confirm the presence of CCR5del32 deletion.

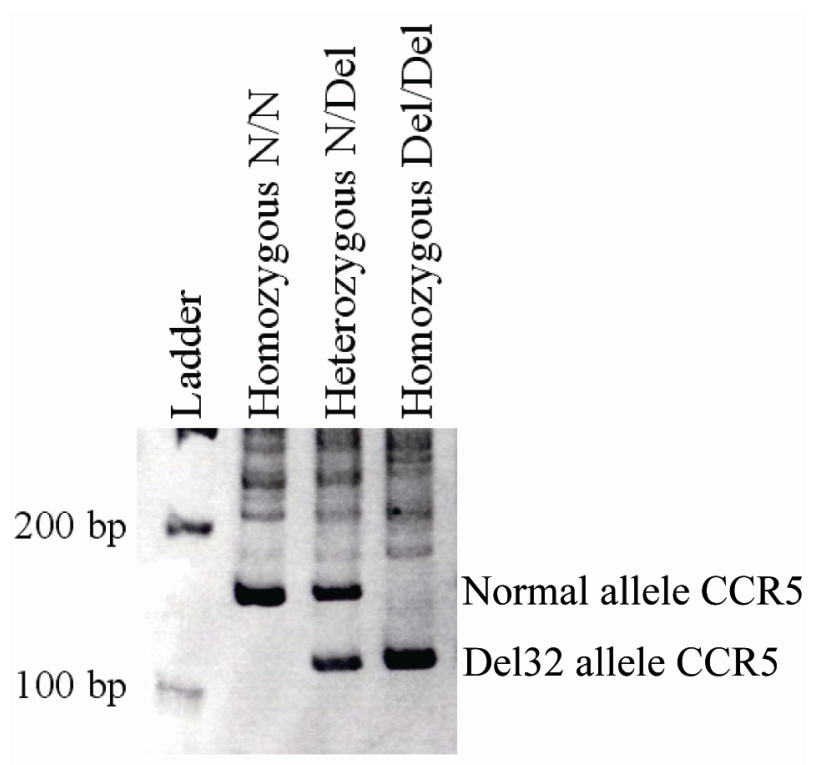

PCR product was assessed by gel electrophoresis and Ethidium Bromide staining. The normal allele corresponds to the $141 \mathrm{bp}$ band while the CCR5-del32 allele corresponds to 109 bp band: N/Del genotype was found in 11 lines heterozygous for deleted allele; Del/Del is the genotype of the parthenogenetic line.

Figure 1. Testing for the CCR5-del32 allele in hESC lines. 


\section{RESULTS AND DISCUSSION}

Of a total of $137 \mathrm{hESC}$ lines tested, 125 were without deletion, 11 were heterozygous for the deletion, and 1 was with two copies of the genes with the deletion (Figure 1). The latter was established from the blastocyst deriving from partenogenetic embryo (46, XX), with two copies of all maternally derived genes, as demonstrated by polymorphic markers for X-chromosome, and chromosomes 3, 6, 11, 13, 18 and 21.

The frequency of the CCR5-del32 allele in the studied material $(4.7 \%)$ is comparable to data published in earlier studies [11], making it realistic to predict the possibility of identification of potentially useful hESC lines conferring resistance to HIV even in smaller collections. Assuming that more than 327 hESC lines are now available in our collection, the testing of the whole material could have led to finding of more than two dozens of hESC lines containing the CCR5-del32 allele conferring resistant to HIV infection.

It may be expected that with the establishment of larger repositories of hESC lines, there may be a possibility to perform a search for finding HLA match for HIV patients. It was predicted that a bank of 150 donor cell lines may already provide a chance of finding full match of HLA-A, HLA-B, and HLA-DR for up to $20 \%$ recipients [12]. With the present progress in the differentiation of hESC into hemopoietic stem cells [13], this material may appear a readily available source of bone marrow transplantation. Clinical implication of the resistant hESC lines will further be widened with the progress in transplantation treatment with unrelated stem cells having significant HLA disparity following the sophisticated immuno-suppression therapy and conditioning of the recipients, which may soon appear routine.

The availability of a hESC lines containing CCR5-32-bp deletion, and particularly a parthenogenetic lines with two copies of this allele, may have particular potential for research into the mechanisms of conferring resistance to HIV, the results of which could lead to new treatments to this most devastating disease. Moreover, the prospective advantages of clinical therapies derived from hESC lines, will likely hold true for many other congenital and acquired diseases. Our repository has a large collection of hESC lines, which provides a unique opportunity to screen available hESC lines for polymorphisms associated with susceptibility and/or resistance to diseases in humans. So this study provides the first evidence that such screening is productive for finding hESC lines with rare mutations which may prove invaluable to the future stem cell therapy of severe disorders for which there is no available treatment.

\section{REFERENCES}

[1] Hütter, G., Nowak, D., Mossner, M., Ganepola, S., Müssig, A., Allers, K., Schneider, T., Hofmann, J., Kücherer, C., Blau, O., Blau, I.W., Hofmann, W.K. and Thiel, E. (2009) Long-term control of HIV by CCR5 Delta32/ Delta32 stem-cell transplantation. New England Journal of Medicine, 360, 692-698.

[2] Liu, R., Paxton, W.A., Choe S., Ceradini, D., Martin, S.R., Horuk, R., MacDonald, M.E., Stuhlmann, H., Koup, R.A. and Landau, N.R. (1996) Homozygous defect in HIV-1 coreceptor accounts for resistance of some multiply-exposed individuals to HIV-1 infection. Cell, 86, 367-377. doi:10.1016/S0092-8674(00)80110-5

[3] Beatty, P.G., Boucher, K.M., Mori, M. and Milford, E.L. (2000) Probability of finding HLA-mismatched related or unrelated marrow or cord blood donors. Human Immunology, 61, 834-840.

zdoi:10.1016/S0198-8859(00)00138-5

[4] Majhail, N.S., Brunstein, C.G., Tomblyn, M., Thomas, A.J., Miller, J.S., Arora, M., Kaufman, D.S., Burns, L.J., Slungaard, A, McGlave, P.B., Wagner, J.E., Weisdorf, D.J. (2008) Reduced-intensity allogeneic transplant in patients older than 55 years: Unrelated umbilical cord blood is safe and effective for patients without a matched related donor. Biology of Blood and Marrow Transplantation, 14, 282-289. doi:10.1016/j.bbmt.2007.12.488

[5] Kleen, T.O., Kadereit, S., Fanning, L.R., Jaroscak, J., Fu, P., Meyerson, H.J., Kulchycki, L., Slivka, L.F., Kozik, M., Tary-Lehmann, M. and Laughlin, M.J. (2005) Recipient-specific tolerance after HLA-mismatched umbilical cord blood stem cell transplantation. Transplantation, 80, 1316-1322. doi:10.1097/01.tp.0000188172.26531.6f

[6] Verlinsky, Y., Strelchenko, N., Kukharenko, V., Shkumatov, A., Rechitsky, S., Verlinsky, O. and Kuliev, A. (2006) Repository of human embryonic stem cell lines and development of individual specific lines using stembrid technology. Reproductive BioMedicine Online, 13, 547550.

[7] Verlinsky, Y., Strelchenko, N., Kukharenko, V., Shkumatov, A., Rechitsky, S., Verlinsky, O. and Kuliev, A. (2009) Isolation of human embryonic stem cells from various stages of the human embryo. In: Lakshmipathy et al. Ed, Emerging Technology Platforms for Stem Cells, Wiley, Hoboken, 19-27. doi:10.1016/S1472-6483(10)60643-8

[8] Robertson, N.J., Brook, F.A., Gardner, R.L., Cobbold, S.P., Waldmann, H. and Fairchild, P.J. (2007) Embryonic stem cell-derived tissues are immunogenic but their inherent immune privilege promotes the induction of tolerance. Proceedingd of the Natiomal Academy Science of the USA, 104, 20920-20925.

[9] Wu, D.C., Boyd, A.S. and Wood, K.J. (2008) Embryonic stem cells and their differentiated derivatives have a fragile immune privilege but still represent novel targets of immune attack. Stem Cells, 26, 1939-1950. doi:10.1634/stemcells.2008-0078

[10] Verlinsky, Y. and Kuliev, A. (2006) Practical preimplantation genetic diagnosis. Springer, London and New York, 198.

[11] Martinson, J.J., Chapman, N.H., Rees, D.C., Liu, Y.T. and Clegg, J.B. (1997) Global distribution of the CCR5 gene 32-basepair deletion. Nature Genetics, 16, 100-103. 
doi:10.1038/ng0597-100

[12] Taylor, C. Bolton, E., Procock, S., Sharples, L., Pederson, R. and Bradley, J. (2005) Banking of human embryonic stem cells: Estimating the number of donor cell lines needed for HLA matching. Lancet, 366, 2019-2025.

doi:10.1016/S0140-6736(05)67813-0
[13] Pryzhkova, M.V., Peters, A. and Zambidis, E.T. (2010) Erythropoietic differentiation of a human embryonic stem cell line harbouring the sickle cell anemia mutation. Reproductive BioMedicine Online, 21, 196-205. doi:10.1016/j.rbmo.2010.04.017 